\title{
Game Theory: Business and Growth Strategies
}

\author{
Mohammad Husain Khan \\ Global Head-Digital Solutions at MarLabs Inc. NY, US \\ E-mail: mohdhusainkhan8483@gmail.com
}

Received: April 20, 2020

Accepted: May 10, 2020

Published: May 25, 2020

doi:10.5296/wjbm.v6i1.16884

URL: https://doi.org/10.5296/wjbm.v6i1.16884

\begin{abstract}
In the present note, we have discussed the growth strategies to enhance the overall business of a company using game theory. An optimal game theory solution happens when one of the companies participating in the game reaches the maximal outcome. Business and growth strategy is an emulsion of not only the innovation of the company but also the ability to access the moves of the competitors.
\end{abstract}

Keywords: Business strategies, Growth, Optimum, Innovation, Backward induction, Quantifiable, Game theory, Nash equilibrium, Rational/irrational. 


\section{Introduction}

Business and growth strategies are a long-term vision that the management creates for the company and requires the joint and active participation from all the decision-makers in the organization to orchestrate that vision. Business strategies can differ drastically based on the size of the organizations i.e. the strategy of a small business would be very different than that of a large corporation. To achieve a goal for any business, the optimum allocation of resources both human and physical is the basic requirement. For the stability, output, and growth of the business, it is imperative for the management to take some crucial decisions. Management's role is very important, they can improve the probability of success for an organization by their strategies.

The business strategy should be crafted taking into account the short and long-term prospects of the business to enhance the profit margin of the business and in turn create value for the shareholders. While there are no cookie-cutter ways to develop business or growth strategies, there are some important and essential stages that successful businesses have had followed:

- Laying out the plans i.e. short as well as the long term by the leadership of the business.

- Sharing the plans or vision with the different team within the company so that all the employees contribute towards achieving the target set by the business.

Business or tactical planning is a short-term method while strategic growth planning is a long-term method for evaluating the steps towards the accomplishment of the business goals. However, the management and leadership should have milestones checks to make sure that the strategy is on track and tweak or completely pivot the strategy if it doesn't achieve the desired milestone results.

This leads us to the most important question: what does business and growth strategy means and entails?

Starting from a small-scale business to a global multinational, the seminal and progressive decisions taken for the development of the vision of the company and creating shareholder value is called business and growth Strategy.

In this modern age, business and growth strategy can be best understood by game theory i.e. an applied mathematics solution tool. It is remarkably useful to evaluate the competitive landscape i.e. a strategic problem where players (marked as parties) make interdependent decisions. To design one's owns strategy each player is supposed to consider the possible decisions and strategies that other players can and would make. The superior decisions of the players that might be similar, contradictory or mingled will decide the outcome. While using game theory strategic setting, two types of players emerge - independent and competing.

\section{Game Theory}

Game theory is often used across multiple verticals such as military strategy, economics, mathematical modeling of strategic interaction among rational (irrational) agents i.e. rationality, philosophy, oligopoly market, poker game, business management and many more. Business 
strategy makers use it to predict about the planning or thinking of their collaborators or competitors. Overall it's a powerful tool to predict the outcomes or consequences of the competitor's interaction and how the landscape should shape up.

The decisions taken by a market contestant will have direct effects on the other players. Hence, affecting the actions of the other players. Under certain rules between two or more players that are involved in this game, its outcomes or quantifiable consequences are modeled on game theory and the solution is called backward induction. In terms of game theory, a well-known mathematician John Forbes Nash Jr (Noble Prize, 1994) proposed that "if each player has chosen a strategy, and no player can benefit by changing strategies while the other players keep theirs unchanged, then the current set of strategy choices and their corresponding payoffs constitutes a Nash equilibrium".

\section{Benefits of Game Theory}

In the present note, I intend to highlight only the benefits of game theory in the business and growth strategies that provide a hypothetical framework. In case, the shared interests of the companies/players are not violated there is no harm to cooperate with the competitors and achieve the goal.

There are three basic components that are seminal to the game theory:

- Game: Let us take two or more companies as the players whose actions are results of known circumstances.

- Strategy: Under the known circumstances i.e. the set of strategies that the players would use during the game time. Therefore, the companies will decide the action plan as per the circumstances in the game.

- Outcome: Outcomes of each set of strategies depends on the expected gain accepted by participating players. When both the players reached consensus/decisions then an outcome is obtainable and the solution is optimal.

There are several assumptions about strategizing the game theory problem. All the players take actions strategically in their self-interest and watch carefully the moves of other competitors. Every player understands the payoffs in a positive as well as a negative strategic context.

Let's take hypothetical example of a company solving its business problem using game theory and help determine the desired outcomes. Let us create a business and growth strategy using game theory for multiple companies as different players.

An established company, A is planning to increase its business and wants to introduce a new product in the market. The business and growth strategies can help predict the revenue that the upcoming product can bring under certain circumstances by setting a game. It is quite possible that the competitors B1 or/and B2 (maybe more than one) may launch similar types of products in the market in the near future. The most important question to ask; what are the thought processes of competitors? What are the competitor's motivations, strengths and weaknesses? Using this information the management team at A can plan preemptively to tilt the game in its 


\section{Macrothink}

favor and increase the business of the new product. This framework adopted by the A leadership will give the optimal profit in this case and is solvable by game theory.

In the present example, the number of Players for the competitive companies is two. Each Player is aware of the rules of play and will move rationally and intelligently to zero sum game i.e. sum of the gains and losses is equal to zero. If Player A gains (number of customers) for his company then the Player B will loss (the same number of customers) for his company.

Assume that two firms A and B are competing. Suppose Player A of a Company has adopted three strategies $A_{1}, A_{2}$ and $A_{3}$ and Player $B$ of the competitor Company had strategies $B_{1}$ and $\mathrm{B}_{2}$ in response to Player A strategies. Secondly, Player B of a Company adopted two strategies $\mathrm{B}_{1}$ and $\mathrm{B}_{2}$ and in response to it Player $\mathrm{A}$ of the competitor Company had strategies $A_{1}, A_{2}$ and $A_{3}$. Then the mathematical model of the above may be represented as follows:

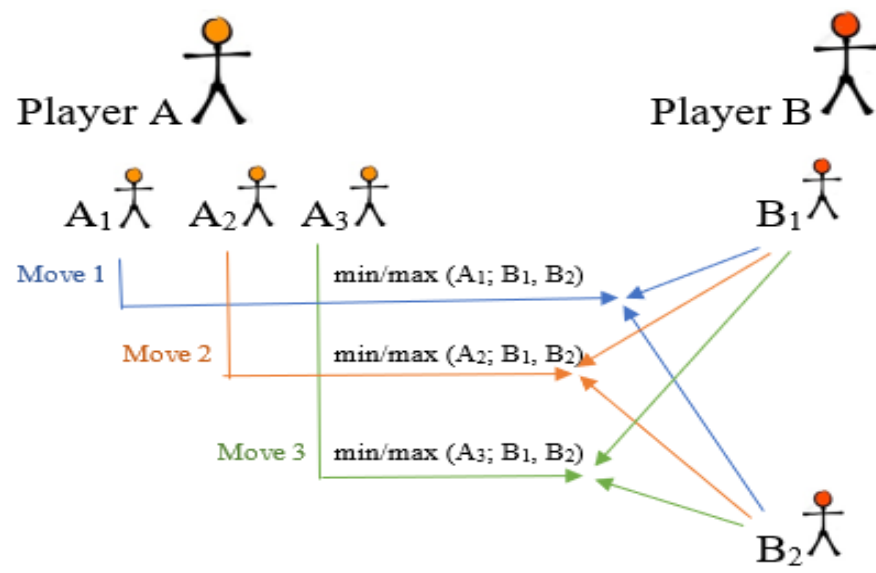

Figure 1. Two Players Game Theory Model of Business 1

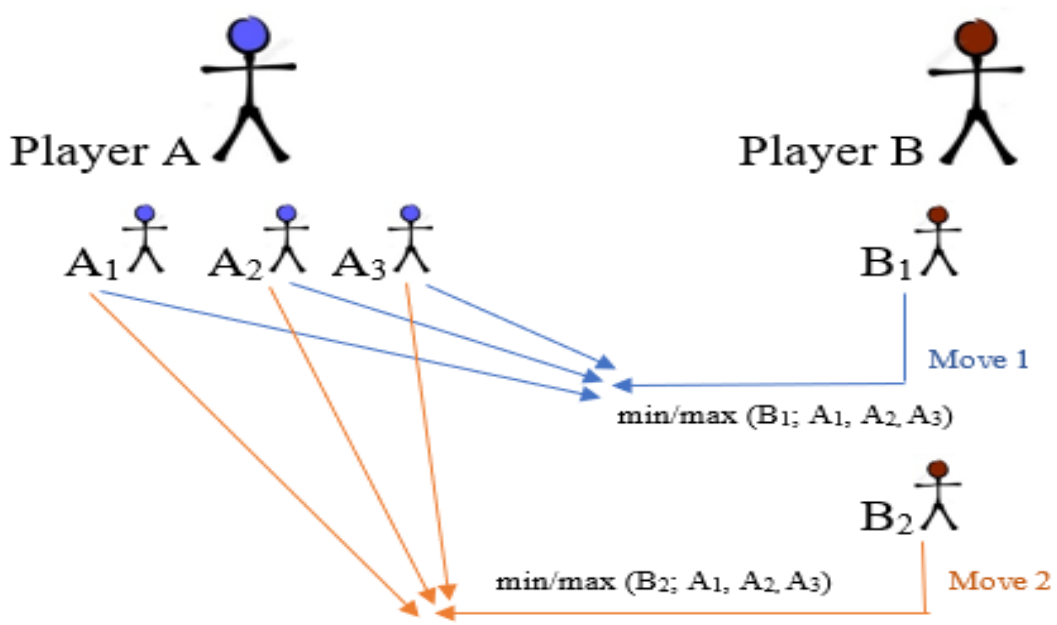

Figure 2. Two Players Game Theory Model of Business 2 


\section{Conclusion}

The solution of the model is given below:

- The best strategy for the Player $A$ depends on the outcome of $\min / \max \left(\mathrm{A}_{1} ; \mathrm{B}_{1}, \mathrm{~B}_{2}\right)$, $\min / \max \left(A_{2} ; B_{1}, B_{2}\right)$ and min/max $\left(A_{3} ; B_{1}, B_{2}\right)$. For example in $\left(A_{1} ; B_{1}, B_{2}\right),\left(A_{2} ; B_{1}, B_{2}\right)$ and $\left(A_{3} ; B_{1}, B_{2}\right)$, the maximum number is attained by $\left(A_{3} ; B_{1}, B_{2}\right)$ then the best strategy for Player $\mathrm{A}$ is $\mathrm{A}_{3}$.

- The best strategy for the Player $B$ depends on the outcome of min/max $\left(B_{1} ; A_{1}, A_{2}, A_{3}\right)$ and $\min / \max \left(B_{2} ; A_{1}, A_{2}, A_{3}\right)$. For example in $\left(B_{1} ; A_{1}, A_{2}, A_{3}\right)$ and $\left(B_{2} ; A_{1}, A_{2}, A_{3}\right)$, the maximum number is attained by $\left(B_{2} ; A_{1}, A_{2}, A_{3}\right)$ then the best strategy for Player $B$ is $B_{2}$.

Case in point - the success in the game depends upon the business leadership's attitude and how they use the game. The above game provides the optimal solution. In the last, we can conclude that achieving profitable growth in any business is heightened if the business has a positive growth strategy and strong execution infrastructure.

In case, the number of players exceeds to more than two then the solution through game theory becomes difficult but is solvable too.

\section{References}

Darren, D. (2019). How to develop the business growth strategy? Inc Magazine. Retrieved from http://www.inc.com (Blog: Growth Through Acquisition).

Frederiksen, L. (2020). Business development strategy: A high-growth approach. Professional services market today. Branding and marketing for professional services. January 15. Retrieved from http://www.hingemarketing.com (Blog: Hinge).

Liabotis, B. (2007): Three strategies for achieving and sustaining growth. IEVY Business Journal. Retrieved from http://www.adelecrane.com (Blog: Adelecrane).

Nash, J. F. Jr. (1997). Essays on game theory (Hard cover). The Amazon Book Review. Retrieved from http://www.amazon.com

Neumann, V. J., \& Moorgenstern, O. (1944). Theory of games and economic behavior. Princeton University Press. Retrieved from http://www.en.wikipedia.org

Picardo, E. (2019). How game theory strategy improves decision-making? Investopedia: Behavioral Economics. May 19. Retrieved from http://www.investopedia.com (Blog: Investopedia).

Pinkasovitch, A. (2018). Game theory and business. Investopedia: Business Essentials. April 16. Retrieved from http://www.investopedia.com (Blog: Investopedia).

Wolfe, L. (2018). Develop better strategies with a business assessment. Women in Business. Balance in career, December 10. Retrieved from http://www.thebalancecareer.com (Blog: Women in business). 


\section{Macrothink}

World Journal of Business and Management

ISSN $2377-4622$ 2020, Vol. 6, No. 1

\section{Copyright Disclaimer}

Copyright for this article is retained by the author(s), with first publication rights granted to the journal.

This is an open-access article distributed under the terms and conditions of the Creative Commons Attribution license (http://creativecommons.org/licenses/by/3.0/). 